\title{
Durkheim y Saint-Simon: La construcción del ideario de la sociedad del trabajo y las nuevas paradojas de las sociedades tardo-modernas
}

\author{
Durkheim and Saint-Simon: The \\ construction of the ideology of the \\ society of the work and the new \\ paradoxes of the late-moderns societies
}

José Francisco Durán Vázquez

tabeiros@hotmail.com

\section{Resumen} El presente artículo tiene como principal objetivo
interrogarse sobre el sentido que poseen las actuales representaciones del trabajo en el contexto del escenario productivo de las sociedades de mercado tardo-modernas. El análisis que aquí se propone interpreta dichas representaciones en relación con la obra de Émile Durkheim y Claude Henri de SaintSimon, por ser dos de los principales autores que más han contribuido a forjar el ideario de las sociedades del trabajo, como un intento de actualización de la estructura simbólica de estas sociedades, con el fin de que continúe manteniendo toda su carga integradora y
legitimadora en relación con las nuevas realidades productivas y laborales.

Palabras clave: Durkheim; Saint-Simon; Trabajo; Keywords: Durkheim; Saint-Simon; Work; Ideology Ideario

\section{Introducción}

Los problemas laborales por los que atraviesan actualmente las sociedades occidentales más industrializadas, han sido interpretados frecuentemente en los últimos años en relación con las transformaciones del modelo productivo tardo-capitalista. Sin embargo, son menos frecuentes los análisis que han considerado estas mutaciones en correspondencia con el universo cultural en el que se inscriben. En esta última perspectiva es en la que queremos ubicar el presente artículo. En él contemplaremos las nuevas representaciones del mundo del trabajo en relación con el orden 
simbólico en el que han surgido, esto es, las modernas sociedades de mercado articuladas en torno a la producción y al trabajo. Dentro de este contexto prestaremos atención al pensamiento de Émile Durkheim y al de Claude Henri de Saint-Simon, por tratarse de dos de los principales autores que más han contribuido, en nuestra opinión, a forjar el ideario de la sociedad del trabajo. La primera parte de este artículo estará dedicado, pues, a examinar someramente la obra de ambos autores desde este punto de vista. En la segunda parte se expondrá como sus ideas acabaron formando parte del sistema de legitimaciones que construyeron las modernas sociedades del trabajo, sobre todo en los países de Europa Occidental después de la Segunda Guerra Mundial. Para finalizar, mostraremos como este sistema de legitimaciones está siendo en parte reelaborado en las sociedades de la modernidad tardía, en consonancia con las alteraciones que están experimentando su modelo productivo.

\section{El contexto social de las propuestas Saint-Simonianas y}

\section{Durkheimianas}

El pensamiento de Saint-Simon y de Durkheim emerge en un contexto presidido por la transformación revolucionaria del Antiguo Régimen y la instauración de un orden social basado en los nuevos principios de la libertad, la igualdad y la fraternidad, que habían sido enarbolados durante la Revolución Francesa. Aun cuando las circunstancias concretas en las que surge la obra de ambos autores son diferentes- Saint-Simon escribe cuando se está iniciando el proceso de industrialización en Francia, al final del Imperio Napoleónico, mientras que Durkheim lo hace en el escenario de la III República francesa, cuando este proceso está ya mucho más avanzado- los dos están animadas por una misma preocupación, a saber, encontrar una solución a la crisis social que, según ellos, todavía permanecía abierta, después de que la Revolución no había sabido construir un orden social estable e integrado a partir de los valores que ella misma había invocado. En este sentido, la obra de Durkheim prolonga la de Saint-Simon, si bien de un modo más formal y menos especulativo, como correspondía a la plena conciencia de saberse el fundador de una nueva ciencia de la sociedad que aún no gozaba de reconocimiento académico.

Para comprender el sentido de las preocupaciones de ambos autores será preciso referirse, aunque sólo sea brevemente, a determinados aspectos relacionados con la crisis de la sociedad estamental y la instauración del régimen liberal.

La Revolución Francesa acabó con el sistema de privilegios corporativos propios de la sociedad estamental, pero también destruyó todo aquel entramado de lazos comunitarios vinculados a dichas corporaciones que protegían a los individuos frente a los distintos infortunios de la vida ${ }^{1}$. En su lugar se fue imponiendo un nuevo discurso, basado en los principios del liberalismo, conforme al cual se establecía que la sociedad era el fruto del acuerdo libre y voluntario de todos aquellos que contribuían con su esfuerzo personal a su engrandecimiento. Así lo entendía el abate Emmanuel Sieyès, al hacer descansar la idea de nación en el Tercer Estado, es decir, en el conjunto de las personas que realizan trabajos útiles para la comunidad, excluyendo de dicho cuerpo político a la nobleza, que por su condición de clase no productiva nada hacía por acrecentar las riquezas del reino (Sieyès, 1789:

1 Sobre el mundo de las corporaciones en el Antiguo Régimen y su transformación después de la Revolución, ver: Sewell , W.H: Trabajo y Revolución en Francia. Taurus. Madrid. 1992 
85-86). Este discurso era el claro heredero de un pensamiento que se remontaba a John Locke (1690), y para el cual el trabajo, por ser considerado el origen de la propiedad y de todas cuantas riquezas habían creado las sociedades humanas, se convirtió progresivamente en una materia de principal interés público y en la base de los derechos políticos. Apoyándose en dichos principios, los liberales propusieron la eliminación de todos aquellos derechos de orden corporativo anclados en la tradición, que limitaban la libre contratación de los trabajadores y las actividades de comercio e industria. Durante el proceso revolucionario francés este discurso adquirió una amplia legitimidad, al proponer, frente a la sociedad estamental y sus distintos sistemas de privilegios vinculados al nacimiento, unos nuevos principios que anulaban las desigualdades heredadas y establecían la libertad y la igualdad ante la ley de todos los hombres que aportaban su esfuerzo al enriquecimiento de la sociedad.

Ahora bien, las contradicciones de este discurso pronto fueron patentes cuando en la última fase de la Revolución Francesa la constitución del año III (agosto de 1795) decretaba que sólo eran sujetos de derechos políticos los propietarios que pagasen algún tipo de renta, quedando excluidos de ellos los ciudadanos que, aún desempeñando alguna función de carácter productivo, no acreditasen la condición de propietarios. Desde este momento el lenguaje liberal se había tornado ambiguo con respecto a sus propios principios. En efecto, si el trabajo productivo había sido presentado como la fuente de los derechos de ciudadanía, por ser el origen de la propiedad y de la riqueza, ¿cómo era posible que la mayoría de los trabajadores, que contribuían sustancialmente con su esfuerzo a la producción de esta riqueza, careciesen de propiedad y por ello también de derechos políticos? El discurso liberal, que se había mostrado tan coherente en su oposición al Antiguo Régimen, comenzaba de esta forma a mostrar sus primeros signos de flaqueza en el preciso momento en que se erigía como la ideología política oficial del nuevo regimen (Sewell, 1980: 377 y ss). Los principios de la igualdad, la libertad y de la solidaridad que lo legitimaban estaban faltos de contenido para una mayoría de la población desprovista de propiedades.

En este contexto es en el que nace la obra de Saint-Simon, cuya principal preocupación será resolver la crisis social abierta con la caída del Antiguo Régimen, mediante la construcción de un sistema social inspirado en los principios de la Revolución Francesa, en el que la producción y el trabajo, por encima de la propiedad, se constituyesen en sus valores supremos. La obra de Durkheim es una continuación de dicho proyecto, pero en un escenario social distinto, en el que ya se han evidenciado las consecuencias sociales del industrialismo, y en el que se ha desarrollado, como respuesta a dicha situación, el pensamiento socialista.

A continuación veremos de qué modo las propuestas saint-simoniana y durkheimiana han contribuido a la legitimación de las sociedades modernas.

\section{Saint-Simon y Durkheim: La construcción del ideario de la sociedad del trabajo}

La obra de Saint-Simon y la de Durkheim nacen en distinta época aunque con una misma preocupación, a saber, resolver la crisis social abierta por la caída del Antiguo Régimen integrando las normas y valores sancionados por la Revolución Francesa en el ideario de las nacientes sociedades industriales. De esta forma ambos autores pretendían llenar de sentido dichos valores, hacerlos significativos para la mayoría de los individuos, consiguiendo por esta vía la ansiada 
integración de estas sociedades. Se trataba, en fin, de poner en relación ambas dimensiones, los principios morales consustánciales a las sociedades modernas con el tipo de actividad que en ellas más predominaba, es decir, la esfera material y la espiritual, con el fin de crear un orden social más armónico e integrado al que se adhirieran todos sus miembros.

La primera tarea que, según ellos, reclamaban, pues, las sociedades modernas era "construir una moral" ${ }^{2}$ ya que "no hay sociedad posible sin ideas morales comunes" (Ansart, 1971: 137). Una moral que esté en consonancia con la producción, función primordial de las modernas colectividades, y con el trabajo, principal actividad que daba impulso a aquella función. La nueva sociedad industrial se concibe así como "la reunión de todos los que trabajan" (Saint-Simon, 1817: 69), como "un vasto cuerpo único, cuyos miembros se complementan sin excepción" (Saint-Simon, 1817: 117), desempeñando la tarea que a cada uno más le convenga (Durkheim, 1893: 440), esto es, la que esté más en consonancia con sus inclinaciones y capacidades, obteniendo en su desempeño "un grado de importancia y de beneficios proporcionales a su capacidad y a su esfuerzo" (Saint-Simon, 1819-1820: 151). La nueva sociedad extraerá así su nueva moral de la actividad que verdaderamente la constituye, el trabajo productivo. En efecto, la igualdad, la libertad, y la solidaridad se materializarán en el mismo espacio productivo, en donde las desigualdades físicas y materiales, que dependen del azar del nacimiento, de la condición familiar", desaparecerían, "para dejar sólo en pie las desigualdades de mérito" (Durkheim, 1937: 280), es decir, aquellas vinculadas con la aportación que cada individuo hace, desde su particular función laboral y merced a su especial capacidad, al conjunto de la comunidad ${ }^{3}$. En estas circunstancias, una vez que todos los individuos se encuentren en una posición semejante, cuando todos ellos sean valorados exclusivamente en orden a sus respectivos talentos, esfuerzos y capacidades en el seno de sus particulares ocupaciones laborales, podrán de una vez por todas, "desarrollar- tal como afirma Saint-Simon- sin cortapisas y en toda su extensión posible, una capacidad temporal y espiritual útil para la asociación” (Durkheim, 1928: 244). Se materializaría así la verdadera libertad, que consiste en que nadie se vea impedido por "ningún obstáculo de cualquier naturaleza que sea (a) ocupar en los cuadros sociales el lugar que está en relación con sus facultades" (Durkheim, 1893: 440).

Se conformaba de esta forma un universo socio-moral, sustentado sobre la actividad laboral, en el que los objetivos individuales se armonizarían perfectamente con los colectivos, materializados en el productivismo de las sociedades de mercado, para dar cumplimiento al ideario de una sociedad articulada en torno al trabajo productivo, imagen por antonomasia de la prosperidad y del progreso individual y colectivo.

La sociedad industrial aparecía así como la fuente de la que emana toda la moralidad, aquella en la que los individuos podrían ver plenamente realizados los valores anunciados por la modernidad; una sociedad que, en definitiva, "sólo nos pide ser afectuosos con nuestros semejantes y ser justos, cumplir bien nuestra misión, trabajar en forma que cada uno sea llamado a la función que mejor pueda llenar, y reciba el justo precio a sus esfuerzos" (Durkheim, 1893: 478)

\footnotetext{
${ }^{2}$ Citado en Introducción de Ramón Ramos Torre en Durkheim (1937: 44).

${ }^{3}$ Más en concreto, según Durkheim (1937) los servicios que cada individuo realiza en favor de la sociedad deberán de ser valorados con arreglo a la utilidad social que producen y al trabajo que cuestan.
} 
El proyecto saint-simoniano y durkheimiano pretendía así dar cumplida respuesta a un programa de ordenación de la sociedad industrial que, partiendo de los presupuestos de las ciencias positivas, se fijaba como principal objetivo la construcción de una nueva moral en correspondencia con las necesidades de la sociedad industrial. Desde esta perspectiva, y asumiendo la estructura de dicha sociedad como parte constitutiva y necesaria de un proceso histórico que había desembocado en las sociedades modernas, se propusieron diseñar un universo social en el que las funciones productivas y laborales, inherentes a estas colectividades, estuviesen en armonía con las representaciones que ellas mismas habían producido. De este modo aspiraban a integrar en un mismo orden socio-moral las relaciones materiales y las espirituales, la estructura productiva de la sociedad industrial, en la que el valor trabajo ocupaba un lugar fundamental, y los principios que la Revolución Francesa había consagrado como signos inequívocos de la modernidad. Por esta razón, por haber contemplado las dos dimensiones de las sociedades modernas en el ámbito de una ciencia social formalizada que otorgaba categoría científica a dicho planteamiento, la sociología de Durkheim y Saint-Simon ${ }^{4}$ acabó siendo incorporada al acerbo ideológico de estas comunidades como uno de sus más potentes instrumentos de legitimación, como la imagen más firme del desarrollo material y moral de la colectividad, llenando así de sentido aquella concepción del progreso que la modernidad había convertido en verdadera categoría moral. En efecto, después de que el Liberalismo y el Socialismo se hubiesen mostrado ineficaces para estabilizar a las sociedades modernas, el uno por su exacerbado individualismo y economicismo, el otro por una orientación decididamente colectivista y revolucionaria, la nueva sociología acabó por adquirir un papel destacado como síntesis de aquellas dos ideologías, al haber combinado sabiamente el individualismo liberal con el colectivismo socialista, sin renunciar por ello a los imperativos de las sociedades de mercado. Este nuevo ideario acabará siendo sancionado por la mayoría de las sociedades occidentales a lo largo del siglo XX, especialmente después de la Segunda Guerra Mundial en el seno de los Estados de Bienestar.

\section{La materialización del proyecto social saint-simoniano y durkheimiano}

A lo largo de la primera mitad del siglo XX los partidos socialdemócratas y liberales de los principales países del Occidente Europeo, en especial Francia, Alemania e Inglaterra, fueron integrando este ideario en sus respectivos programas políticos. Conforme al mismo, los gobiernos de estos países diseñaron, con posterioridad a la Segunda Guerra Mundial, un proyecto socio-político, conocido como Estado del Bienestar ${ }^{5}$, cuyo objetivo esencial era la incorporación de la mayoría de la población al empleo asalariado, vinculando a quienes disfrutaban de esta situación, así como a los que no pudiesen hacerlo por alguna razón ajena a su voluntad relacionada con una incapacidad objetiva o con el paro forzoso, una serie de privilegios en forma de derechos, que facilitaban simultáneamente

\footnotetext{
${ }^{4}$ En especial la del primero, que como se sabe entroncó con el proyecto socio-político de la Tercera República Francesa. La sociología de Saint-Simon, por el contrario, al pertenecer a una época donde todavía no eran muy visibles los signos del industrialismo, tuvo un carácter más profético que científico.
}

${ }^{5}$ Sobre el Estado del Bienestar se pude consultar: Offe (1988); Ashford (1986); Esping-Andersen (1990). 
su integración social y el desarrollo de la economía de mercado. Estos derechos contribuían, además, a la creación de lazos de solidaridad entre los que no podían trabajar, aún queriendo, y aquellos otros que, por el contrario, sí podían hacerlo. Su existencia impedía, asimismo, que las personas que careciesen temporalmente de ocupación se entregasen a formas de subsistencia distintas a las del empleo. La condición era siempre la misma, la disposición de la mayoría de la población a integrarse en alguna esfera del trabajo asalariado y una situación cercana al pleno empleo. Situación que se dio en esta época en la mayoría de los países democráticos europeos (Esping-Andersen, 1990: 221225).

El éxito que alcanzó el Estado del Bienestar después de la Segunda Guerra Mundial, representó en buena medida la culminación práctica del proyecto que Saint-Simon y Durkheim habían diseñado para las sociedades modernas. En efecto, tal como ellos habían sostenido, el trabajo se había convertido en el verdadero vínculo social; aquella actividad por medio de la cual se construían relaciones más solidarias, y cuyo desempeño se identificaba con los valores de igualdad y libertad que habían consagrado las sociedades modernas. Las ocupaciones laborales, en este momento ya bajo la forma de empleo, aparecían como el ámbito en el que se podría alcanzar un grado elevado de autonomía y de desarrollo personal, cualquiera que fuese el origen social del que se partiese. De hecho, éste era el sentido que William Beveridge, el padre del Estado del Bienestar Británico, atribuía a una política de pleno empleo: "La política que se expone en este informe-escribía- (...) proporciona la oportunidad de ejercer las facultades naturales, dentro de una emulación generosa con nuestros semejantes". "La esencia de la democracia- sostenía en otro lugar de este mismo escrito- es que los hombres puedan acceder a la dirección y a las responsabilidades, independientemente de su ocupación anterior y de su origen" (Beveridge, 1944: 320-323). La sociedad del trabajo se constituía de este modo en el espacio más idóneo para el desarrollo de los valores democráticos, ya que en su seno los individuos podrían demostrar libremente sus capacidades, sin ningún freno relacionado con la herencia.

En una situación próxima al pleno empleo, como la que caracterizó a los países democráticos de Europa Occidental con posterioridad a la Segunda Guerra Mundial, este ideario fue incorporado por un buen número de personas que proyectaron sus esperanzas de movilidad social en la consecución de un empleo estable y duradero. Desarrollo personal y social parecían estar estrechamente vinculados, proporcionando un claro sentido a la idea de progreso que la modernidad había conformado.

A esta sensación de progreso y estabilidad contribuyó también el crecimiento económico continuado que caracterizó a este periodo, y que se prolongó hasta mediados de los años setenta. Este dinamismo de la actividad económica permitió sufragar los gastos de un Estado del Bienestar en expansión, gastos que, a su vez, sirvieron para impulsar nuevamente el desarrollo económico por medio de la activación de la demanda.

Los Estados del Bienestar parecían haber materializado el proyecto social que Saint-Simon y Durkheim habían imaginado para las sociedades modernas. Por medio de su acción se había consolidado una sociedad estructurada alrededor del trabajo asalariado, en donde las funciones productivas se compatibilizaban con los valores que la modernidad había encumbrado. En una misma realidad social vertebrada por el trabajo productivo se armonizaban por fin las actividades materiales con los valores morales, para componer una imagen de la sociedad que se ajustaba a aquella otra que la mentalidad moderna había creado. Las sociedades industriales se habían dotado así de un 
Durkheim y Saint-Simon: La construcción del ideario de la sociedad del trabajo y las nuevas paradojas de las sociedades tardomodernas

José Francisco Durán Vázquez

universo simbólico, en correspondencia con las principales actividades que las organizaban, que las mantenía cohesionadas e integradas.

Esta situación se mantuvo estable hasta mediada la década de los setenta, fecha a partir de la cual las economías más desarrolladas del mundo occidental, sobre todo las europeas, comenzaron a experimentar importantes transformaciones, que han incidido finalmente en las representaciones que habían sido elaboradas por las sociedades industrializadas con respecto al mundo del trabajo. El último epígrafe del presente artículo estará dedicado precisamente a mostrar el impacto que tuvieron estas transformaciones en el universo simbólico que las sociedades modernas habían construido alrededor del mundo del trabajo.

\section{Las transformaciones de la sociedad del empleo}

Desde las últimas décadas del siglo XX el escenario socio-productivo de las sociedades de mercado se ha visto seriamente alterado. Muchos de los países integrados en la OCDE experimentaron importantes descensos tanto en los índices de productividad como en los de paro ${ }^{6}$. La caída de la productividad y del empleo reforzó la crisis del Estado del Bienestar, al disminuir los ingresos y aumentar, por el contrario, los gastos destinados a cubrir los seguros de desempleo; gastos que, por otra parte, tenían que ser atendidos por un número cada vez menor de población activa. Después de casi tres décadas parecía que comenzaba a resquebrajarse el equilibrio entre las funciones sociales y las económicas, base del orden social en las modernas sociedades de mercado.

Para enfrentar la crisis, una de cuyas manifestaciones más evidentes desde el punto de vista económico fue la saturación de los mercados de consume (Piore y Sabel, 1984: 263-64), las distintas unidades productivas se vieron en la necesidad de flexibilizar la producción, reajustándola a las nuevas circunstancias de la demanda, creando productos cuyo atractivo procedía de su especial singularidad que constantemente se resaltaba. Con el fin de adaptarse a los vaivenes del mercado y reducir sus costes, las empresas realizaron asimismo importantes inversiones en tecnología ${ }^{7}$. El resultado de todo ello fue la aparición de un nuevo modelo productivo con una mano de obra menos estable y más reducida, en clara correspondencia con la inestabilidad de la demanda y una alta inversión en tecnología. La reducción del empleo y las inseguridades laborales que acompañaron a la nueva organización de la producción postfordista, han generado una creciente separación entre las dos principales actividades que mantenían integradas a las sociedades de mercado, a saber, la producción y el trabajo. En el periodo anterior, coincidiendo con el auge del Estado del Bienestar, ambas actividades se potenciaron mutuamente. Los incrementos constantes de la productividad, cuyo objetivo proclamado era el aumento de la riqueza, aparecían como la principal expresión del progreso social, progreso al que el trabajo servía de modo fundamental, no sólo por su contribución primordial a la generación de dicha riqueza, sino también por ser percibido como la condición esencial para el

\footnotetext{
${ }^{6}$ Ver: OCDE (1994: 29); Lapuente y Ortiz (2000: 99).

${ }^{7}$ La creciente separación entre productividad y empleo, característica del nuevo sistema productivo salido de la crisis, es resaltado por numerosos autores, así como por algunos organismos internacionales de gran relevancia. Ver: Le Bris (1997: 109-110); Rifkin (1996:18-19 y 175 y s); Beck (1999: 46); Comisiones de las Comunidades Europeas (1993: 137); Comisión Europea (1999: 59); OCDE (1991: 168).
} 
desarrollo y la integración de los individuos en el seno de una sociedad cada vez más solidaria. En este contexto, el ideario de la sociedad del trabajo, que Saint-Simon y Durkheim tanto habían hecho por legitimar, resultaba especialmente palpable para una mayoría de la población que vinculaba su identidad y sus esperanzas de desarrollo individual y de movilidad social al desempeño de un empleo relativamente seguro, que fuese además la expresión de la contribución que cada individuo realizaba en favor de la colectividad.

Sin embargo, en las dos últimas décadas del siglo XX las transformaciones productivas anteriormente señaladas han erosionado el imaginario de las sociedades del trabajo, por cuanto los signos del desarrollo individual y social, los medios principales de integración social y del progreso material, el trabajo y la producción, ya no actúan con la armonía de antaño. Los incrementos de la productividad repercuten cada vez menos en favor de un empleo más abundante, seguro y estable (Le Bris, 1997: 109-110), con el riesgo de debilitar los valores que la modernidad había construido alrededor del ejercicio de la actividad laboral. Ahora bien, la dificultad para salir de una situación como esta procede del hecho de que las sociedades modernas siguen precisando para mantenerse integradas de la producción y del trabajo, con el objetivo de atender simultáneamente a la creación de riqueza y a la estructuración de la sociedad, en conformidad con los valores que la modernidad había legitimado. En otros términos, las sociedades modernas reclaman para mantenerse integradas, tal como habían planteado Durkheim y Saint-Simon, un orden material y simbólico estrechamente vinculados. No obstante, la dificultad actual radica en que dicha estructura simbólica puede perder muchos de sus significados anteriores en unas circunstancias presididas por el paro y la inestabilidad laboral. Ante esta situación, las sociedades modernas deben restaurar estos significados en consonancia con los requerimientos del nuevo modelo productivo, sin por ello socavar el ideario de la sociedad del trabajo: "Nuestras sociedades- se afirma en un documento de la Comisión Europea- se ven impelidas a encontrar nuevos medios más apropiados para incitar a sus miembros a participar en la producción y en la vida social" (Comisión Europea, 1999: 53). En este contexto es en el que, a nuestro entender, surgirían los nuevos discursos laborales.

\section{La recomposición del ideario de la sociedad del empleo y la aparición de los nuevos discursos laborales}

La pretensión última de las nuevas representaciones laborales, emergentes en el escenario social que en el apartado anterior hemos descrito, sería precisamente reafirmar los valores de la sociedad del trabajo cuando estos más se podrían ver cuestionados:
“Jamás la función 'irremplazable', 'indispensable' del trabajo en tanto que fuente de lazo social, de 'cohesión social', de 'integración', de 'socialización', de 'identidad personal', de sentido, ha sido invocada tan obsesivamente como desde que no puede llenar ninguna de esas funciones." (Gorz, 1997: 67).

A esta tarea se han dedicado especialmente las élites políticas y empresariales, los autores del denominado management, así como los intelectuales relacionados con estas instancias. Desde estos planteamientos se aspiraría a recomponer el orden simbólico que la modernidad había construido en torno al trabajo productivo, que en el presente artículo hemos visto ejemplificado en la obra de SaintSimon y de Durkheim. Estos discursos pretenderían reformular los aspectos de este orden simbólico que más se han visto afectados por la crisis. Desde esta perspectiva es cómo se podría comprender 
sus frecuentes invocaciones al cambio permanente, a la adquisición de nuevas competencias laborales o a la participación e integración de los trabajadores en la denominada empresa ciudadana.

Las frecuentes alusiones al cambio permanente que realizan los actuales discursos laborales, encuentran su explicación en el ámbito del nuevo escenario laboral que se inauguró en muchas de las economías más desarrolladas en las dos últimas décadas del siglo XX, lo que finalmente ha repercutido en la idea de progreso que la modernidad había vinculado a los procesos productivos y laborales. Mientras que en las décadas precedentes el crecimiento económico coincidía con el ingreso de nuevas cohortes de población en el mundo del trabajo, al que se asociaban una serie de proyectos personales futuros componiendo una misma imagen del tiempo que se reforzaba mutuamente; en el contexto social actual, poblado de mayores incertidumbres e inseguridades laborales, el desarrollo económico, uno de los principales indicadores de aquella idea de progreso, ya no se corresponde como antes con las posibilidades que ofrece el mundo del empleo. En estas circunstancias, la idea de tiempo que habían instaurado las sociedades modernas, una de cuyas manifestaciones más tangibles residía en el mundo del trabajo, podría perder su dimensión más movilizadora e integradora, por lo que se hace preciso reformularla, sin erosionar por ello la tradición de la que procede. Dicho de otro modo, las sociedades de mercado deben reformular este concepto en relación con las dos principales actividades que la articulan, el trabajo y la producción, para que así conserven su capacidad integradora, sin romper, sin embargo, el marco cultural en el que aquel concepto fue formulado. Los nuevos discursos atribuyen de este modo al cambio un significado positivo, en relación con la idea de progreso que las propias sociedades modernas habían construido. Ahora bien, este cambio ya no se concibe, como en épocas anteriores de mayor estabilidad laboral, en relación con la posibilidad de planificar el futuro desde la seguridad que proporcionaba el presente. Por el contrario, cuando este presente se hace más inseguro, el cambio se instala como algo inminente, al que los sujetos no tendrían más remedio que estar adaptándose continuamente. Por decirlo en el lenguaje institucional, los individuos deberán de "actuar de manera preventiva desarrollando capacidades para enfrentarse al cambio" (OCDE, 1991: 140). No obstante, para que esta apelación al cambio mantenga el carácter movilizador de otras épocas, es necesario recubrirlo con la carga simbólica que le había otorgado la modernidad, es decir, vincularlo con un tiempo futuro, que siga siendo expresión de la idea de progreso. Sin embargo, este futuro ya no podrá ser un tiempo aplazado, en virtud las inseguridades del presente, sino una realidad inminente ante la que hay que estar constantemente preparado y expectante. Es un tiempo que Niklas Luhmann ha denominado muy gráficamente futuro-presente (Luhmann, 1976: 153 y ss), por ser el futuro quien se está actualizando permanentemente como presente, dotando a éste de nuevos significados. Desde este punto de vista, se pretende que los sujetos no sólo se anticipen al cambio (Drucker, 1999: 111), sino que lo vean como una oportunidad para progresar, es decir, para perfeccionar sus conocimientos y capacidades laborales:

"Las empresas dispuestas al cambio- escriben los autores del management- cultivan la imaginación para innovar...sus empleados son descubridores de ideas en busca de innovación, profesionales que persiguen conocimientos cada vez más completos." (Moss Kanter, 1997: 22).

El cambio, en cuanto supone la ampliación y la renovación permanente de las capacidades laborales, se presenta como una ocasión extraordinaria para el desarrollo personal y colectivo, esto es, para el progreso de los sujetos en el marco de las actuales organizaciones empresariales. En este contexto se genera una creciente preocupación por la formación permanente. La importancia otorgada a la 
Durkheim y Saint-Simon: La construcción del ideario de la sociedad del trabajo y las nuevas paradojas de las sociedades tardomodernas

José Francisco Durán Vázquez

formación en los actuales discursos laborales corre paralela, sin embargo, con la pérdida de valor de muchas titulaciones académicas.

En efecto, a diferencia de lo que había ocurrido en las sociedades occidentales en las tres décadas posteriores al término de la Segunda Guerra Mundial, en donde los lazos existentes entre el sistema educativo y el laboral eran muy estrechos, en la actualidad estos vínculos se han hecho mucho más laxos. Aunque las oportunidades de encontrar un empleo son todavía mayores para los que poseen certificados académicos, éstos ya no garantizan como antes la consecución de un empleo relacionado con estos credenciales, en el que además sea posible desarrollar una carrera segura y estable $^{8}$. En estas circunstancias se podría resquebrajar aquel ideario vinculado al mundo moderno, que formaba parte sustancial del proyecto durkheimiano y saint-simoniano, conforme al cual se establecía una fuerte vinculación entre la capacidad y la posición que los individuos ocupaban en el espacio laboral. El mérito y la capacidad se erigieron así en los criterios esenciales para ordenar las sociedades modernas, de un modo que fuese considerado legítimo para sus miembros. Para que este ideario siga preservando su sentido originario en el contexto de las realidades laborales tardomodernas, es preciso que su contenido sea en parte modificado, si quiere conservar el mismo carácter movilizador e integrador de otras épocas. En otras palabras, sigue siendo necesario que exista una fuerte relación entre los procesos formativos y los laborales, pero en unos términos que se adecuen a las condiciones laborales actuales. En este sentido el concepto de formación ha adquirido un sentido más lato, sobrepasando el ámbito estricto de las titulaciones académicas. En efecto, desde la esfera de la gestión empresarial y de las instituciones públicas, se insiste en que los sistemas productivos actuales en cambio permanente exigen un tipo de cualificación que no se agota en los meros certificados académicos. Es más, se afirma incluso "que las instituciones académicas dispensan cada vez menos conocimientos y cualificaciones necesarias para cuando los alumnos comiencen a trabajar" (OCDE, 1992: 9-10), debido a que el nuevo mundo del trabajo necesita menos de cualificaciones objetivas que den acceso a títulos de validez permanente, que de un conjunto de habilidades que es preciso estar renovando continuamente en contacto con el propio proceso productivo. Estas habilidades se agruparían en un conjunto de disposiciones subjetivas, tales como: "creatividad, iniciativa, aptitud para la resolución de problemas, flexibilidad, capacidad de adaptación, responsabilidad, aptitudes de aprendizaje y reciclaje, todas ellas necesarias para una época de cambio imprevisible y sin precedentes" (OCDE, 1992: 30). A través de la adquisición de estos nuevos conocimientos los sujetos tardo-modernos ampliarían sus capacidades, y por ello también sus posibilidades de promoción y de desarrollo personal:

"¿Cómo atender al doble apremio de la necesidad de una evolución permanente y de la estabilidad psicológica ligada a un determinado rango y a una remuneración? La solución es vincular la cualificación y el rango, no ya con un diploma de partida...sino con las competencias realmente ejercidas." (Génelot, 1992: 213).

\footnotetext{
${ }^{8}$ Si bien es cierto que las empresas demandan cada vez más a trabajadores con algún tipo de cualificación, también lo es que se ha producido un incremento del paro entre las personas cualificadas. Concretamente, en el área OCDE, aunque en la década de los ochenta aumentó la cifra de personas con titulación media o superior, "sin embargo la tasa de aumento de la proporción de la población trabajadora que tiene estudios universitarios o equivalentes se desaceleró en esta época en comparación con las anteriores". Ver OCDE (1994: 53 y 114). Para el caso de España se puede consultar Cachón Rodríguez (2000).
} 
Se pretendería de esta forma continuar promoviendo la movilización y la motivación de los sujetos con respecto al mundo del trabajo, aunque para ello se apele más al concepto de competencia que al de cualificación, más desgastado por la pérdida de validez de los títulos académicos. Dicho de otro modo, una vez que las credenciales académicas ya no permiten como en otro tiempo asignar posiciones estables dentro del ámbito laboral con expectativas de desarrollo para quienes las poseen, son las competencias quienes están llamadas a desempeñar esta misma función con el objetivo de recomponer el orden simbólico vinculado a las sociedades modernas. Las numerosas incertidumbres que produce el mundo del trabajo tardo-moderno se tornarían de este modo en fuente de numerosas oportunidades, en nuevas posibilidades de progreso para los individuos que en él se integran. El espacio laboral se transforma así para los portadores de estos discursos en un ámbito abierto a todas las manifestaciones de la personalidad de los sujetos. En efecto, en el nuevo "modelo de trabajo, el individuo cuenta de nuevo", puesto que en el se potencia "toda la personalidad en su conjunto" (Landier, 1992: 130). En este contexto emergerá la imagen de la nueva empresa, en la que los progresos individuales confluirán con los colectivos en el ámbito de un proceso laboral cooperativo orientado hacia unos mismos fines productivistas.

No obstante, estos fines aparecerán ahora expresados en los términos del nuevo lenguaje laboral postfordista. En efecto, sin en la etapa Taylorista-Fordista la empresa declaraba abiertamente su pretensión acumuladora, ahora justificará su acción en la necesidad de prestar una atención más individualizada y de mayor calidad a sus potenciales clientes. Por decirlo con las palabras de los autores de la nueva gestión empresarial:

"En la empresa Taylorista, el management se interesaba en particular... por la evolución cuantitativa de una parte de las producciones...el otro 'management' se interesa por priorizar la introducción de los progresos de todo tipo en las estructuras empresariales y en la mejora de la calidad de los productos, así como de la vida de la empresa." (Archier y Sérieyx, 1984: 136-137).

Esta apuesta por la calidad otorgaría un nuevo sentido a la acción laboral que se desenvuelve en su seno. Tal como afirman los defensores de este nuevo modelo productivo, "por la calidad el trabajo podrá ser reencantado" (Le Goff, 1992: 70-71). Esta nueva misión de la empresa, concepto clave de los nuevos discursos laborales, justificaría la implicación de todos cuantos allí trabajan en un mismo proyecto, que se revelaría a la vez útil para la sociedad y para el conjunto de sus miembros. La misión, al ser la expresión de unos mismos objetivos compartidos, conformará una única visión de la organización empresarial, de la cual participarán el conjunto de los que en ella se integran. Efectivamente, "cuanto más común es la visión vinculada a un contexto de trabajo, mayores son las oportunidades de observar a los distintos participantes comprometerse e integrarse" (Aktouf, 1999: 614). Si bien dicho compromiso no obstaculizará la libertad de expresión de todos sus componentes.

"La empresa y los individuos mantiene así una relación dialéctica. Los individuos deben ser portadores de la totalidad y la totalidad portadora de los individuos, para que la empresa se convierta en un lugar vivo, un lugar donde la identidad individual pueda desarrollarse sin exclusión ni alienación." (Génelot, 1992: 194).

Las nuevas relaciones laborales harían así innecesarias cualquier clase de jerarquías, toda vez que los individuos se mostrarían por igual interesados en adherirse a unos mismos objetivos colectivos: "Cada vez más los "empleados" tienen que ser gestionados como "socios", y según la definición de sociedad todos los socios son iguales" (Drucker, 1999: 43). En este contexto, se abandonaría la 
Durkheim y Saint-Simon: La construcción del ideario de la sociedad del trabajo y las nuevas paradojas de las sociedades tardomodernas

José Francisco Durán Vázquez

antigua "moral de sujeción" propia del fordismo por una "moral de cooperación libremente aceptada" (Landier, 1992: 177)

Los nuevos discursos laborales pretenderían de este modo trasladar al espacio empresarial postfordista muchos de los significados que Durkheim y Saint-Simon habían construido alrededor del mundo del trabajo. Dicho de otro modo, cuando la producción y el trabajo, elementos fundamentales de la estructura material de las sociedades de mercado, se corresponden cada vez menos con el universo simbólico que estas mismas colectividades han creado, la empresa se presenta, en el contexto de los actuales discursos laborales, como el lugar idóneo para recrear aquel conjunto de significados. La empresa se convertiría así en un lugar de encuentro entre los proyectos personales y los colectivos, en el que cada individuo hallaría el lugar más acorde con sus aptitudes y capacidades laborales. En su interior querría recrearse, en fin, aquel ideario que Durkheim y Saint-Simon habían concebido en consonancia con los valores de las sociedades modernas, ideario que las nuevas representaciones laborales desearían ver realizado en el espacio más reducido de las actuales organizaciones productivas:

"Las organizaciones sólo podrán adaptarse a un mundo diferente y encontrar los medios para llevar a cabo su misión de una forma eficaz, si los que trabajan en ellas sienten de verdad que la divisa de la República- 'libertad, igualdad, fraternidad'- está vigente en todas partes y para todos." (Sérieyx, 1993: 316).

La empresa ciudadana se presenta de este modo como una totalidad organizada por las distintas funciones laborales de cada uno de sus miembros, en la que sería posible la realización de los valores de las sociedades modernas. En efecto, en su interior todos los individuos serían valorados con arreglo a las capacidades que demuestren en el ejercicio de sus respectivas funciones laborales, al servicio de un objetivo común representado por el ideal de la sociedad de servicios. La empresa trascendería así su dimensión meramente productiva para adquirir un claro contenido moral, en el que finalmente encontrarían acomodo los principios universales de la Revolución Francesa.

Los nuevos discursos laborales suponen así un intento de recomponer la relación salarial en las sociedades de mercado tardo-modernas, recurriendo para ello al sistema de legitimaciones que Durkheim y Saint-Simon habían proyectado sobre las sociedades modernas. Si la obra de aquellos dos autores encontraba uno de sus más claros sentidos en la pretensión de diseñar un sistema social en el que las realidades productivas se conjugasen con los ideales de las sociedades modernas, los actuales discursos laborales pretenderían retomar este proyecto por medio de la actualización de aquellos ideales en contacto con las circunstancias productivas de las sociedades tardo-modernas.

\section{Referencias}

Aktouf, Omar. (1999). Le management entre tradition et renouvellement. Montreal: Gaëtan Morin.

Ansart, Pierre. (1971). Sociología de Saint-Simon. Barcelona: Península, 1972.

Archier, Georges y Sérieyx, Hervé. (1984). L'entreprise du troisième type. París: Éditions du Seuil.

Arendt, Hannah. (1958). La condición humana. Barcelona: Paidós, 1998 
Durkheim y Saint-Simon: La construcción del ideario de la sociedad del trabajo y las nuevas paradojas de las sociedades tardomodernas

José Francisco Durán Vázquez

Ashford, Douglas. (1986). La aparición de los Estados del Bienestar. Madrid: Ministerio de Trabajo y Seguridad Social, 1989.

Beck, Ulrich. (1986). La sociedad del riesgo. Barcelona: Paidós, 1998.

Beck, Ulrico. (1999). Un nuevo mundo feliz. Barcelona: Paidós, 2000.

Besnard, Philipe. (1993). Les pathologies des societés modernes. En Philipe H. Besnard, Michel Borlandi y Pierre Vogt (Ed.). División du travail et lien social. Durkheim un siècle après (pp 197-211). París: PUF, 1993.

Beveridge, William (1944a) Pleno empleo en una sociedad libre. Madrid: Ministerio de Trabajo y SS. 1989

Blau, Peter M. y Milby, Richie L. (1993) Faits sociaux et structure sociale. En Philippe H. Besnard, Michel Borlandi y Pierre Vogt. (Ed.) División du travail et lien social. Durkheim un siècle après (pp 135-145) París: PUF.

Cachón Rodríguez, Lorenzo. (2000). Los jóvenes en el mercado de trabajo en España. En Lorenzo Cachón Rodríguez (Ed.). Juventudes y empleos. Perspectivas comparadas (pp 11-23) Madrid: Instituto de la Juventud.

Castel, Robert. (1995). Las metamorfosis de la cuestión social. Buenos Aires: Paidós, 2001.

Comisión de las Comunidades Europeas. (1993). Crecimiento, competitividad y empleo. Luxemburgo: Oficina de publicaciones oficiales de la Comunidades Europeas

Comisión Europea. (1999). L'avenir du travail. Luxemburgo: Office de publications officielles des communautés européennes.

Drucker, Peter. (1999). El management del siglo XXI. Barcelona: Edhasa, 2000.

Durkheim, Émile. (1893). La división del trabajo social. Madrid: Akal, 1995.

Durkheim, Émile. (1895). Las reglas del método sociológico. Madrid: Akal, 1985.

Durkheim, Émile. (1925). La educación moral. Madrid: Morata, 2002.

Durkheim, Émile. (1928). El socialismo. Madrid: Editora Nacional, 1982.

Durkheim, Émile. (1937). Lecciones de sociología. Buenos Aires: Schapire, 1966.

Esping-Andersen, Gosta-Esping. (1990). Los tres mundos del Estado del Bienestar. Valencia: Alfons el Magnànim, 1993.

Genelot, Dominique. (1992). Manager dans la complexité. París: Insep éditions.

Gorz, André. (1991). Metamorfosis del trabajo. Madrid: Sistema, 1997.

Gorz, André. (1997). Miserias del presente, riqueza de lo posible. Buenos Aires: Paidós, 2000.

Isambert, François André. (1993). La naissance de l'individu. En Philippe H. Besnard, Michel Borlandi y Pierre Vogt. (Ed.). División du travail et lien social. Durkheim un siècle après (pp 113-133) París: PUF. 
Durkheim y Saint-Simon: La construcción del ideario de la sociedad del trabajo y las nuevas paradojas de las sociedades tardomodernas

José Francisco Durán Vázquez

Landier, Hubert. (1992). Hacía la empresa inteligente. Bilbao: Deusto SA

Lapuente Perernau, Jordi y Ortiz de Villacian Rebollo, Daniel. (2000) Las políticas laborales. En José Adelantado (Ed.). Cambios en el Estado del Bienestar (pp 99-133). Barcelona: Universitat Autónoma de Barcelona.

Le Bris, Robert. (1997). Crise du concept d'emploi et droit du travail. En Paul Boutarffigue y Henri Eckert. Le travail à l'epreuve du salariat (pp 71-93). París: L'Harmattan.

Le Goff, Jean-Pierre. (1992). Le mythe de l'entreprise. París: La Découverte.

Locke, John. (1690). Segundo Tratado sobre el Gobierno Civil. Madrid: Alianza Editorial, 1990.

Luhmann, Niklas. (1976). El futuro no puede empezar: estructuras temporales en la sociedad moderna. En Ramón Ramos Torre. Tiempo y sociedad (pp 130-152). Madrid: CIS, 1992.

Lukes, Steven. (1973). Émile Durkheim. Su vida y su obra. Madrid: SXXI, 1984

Méda, Dominique. (1995). El trabajo, un valor en peligro de extinción. Barcelona: Gedisa, 1998.

Miller, W. Watts. (1993). Les deux préfaces: Science morale et reforme morale. En Philippe H. Besnard, Michel Borlandi y Pierre Vogt. (Ed.). División du travail et lien social. Durkheim un siècle après (pp 147-173). París: PUF.

Moss Kanter, Rosabeth. (1997). Las nuevas fronteras del management. Barcelona: Paidós, 1999.

Moya, Carlos. (1970). Sociólogos y sociología. Madrid: SXXI, 1970.

OCDE. (1991). Políticas de mercado de trabajo en los noventa. Madrid: Ministerio de Trabajo y Seguridad Social.

OCDE. (1992). Écoles et entreprises. París: OCDE.

OCDE. (1994). Estudio sobre el empleo (Parte I). Madrid: Ministerio de Trabajo y Seguridad Social, 1997.

Offe, Claus. (1988). Contradicciones en el Estado del Bienestar. Madrid: Alianza Universidad, 1990.

Piore, Michael J. y Sabel, Charles F. (1984). La segunda ruptura industrial. Madrid: Alianza Universidad, 1990.

Polanyi, Kart. (1944). La gran transformación. Madrid: La Piqueta, 1997.

Reynaud, Jean-Daniel. (1993). La formation des règles sociales. En Philippe H. Besnard, Michel Borlandi y Pierre Vogt. (Ed.). División du travail et lien social. Durkheim un siècle après (pp 295-305) París: PUF.

Rifkin, Jeremy. (1996). El fin del trabajo. Paidós. Barcelona.

Russ, Jacqueline. (1973). Los precursores de Marx. Barcelona: Novaterra, 1976.

Sadri, Mahmoud y Stinchcombe, Arthur. (1993). La modulation de l'assigné et de l'acquis dans les societés modernes. En Philippe H. Besnard, Michel Borlandi y Pierre Vogt. (Ed.). División du travail et lien social. Durkheim un siècle après (pp 279-285). París : PUF. 
Durkheim y Saint-Simon: La construcción del ideario de la sociedad del trabajo y las nuevas paradojas de las sociedades tardomodernas

José Francisco Durán Vázquez

Saint-Simon, Claude-Henri (1807-08) Introduction aux travaux scientifiques du XIX siècle. En: uvvres de C.H de Saint-Simon (Tomo VI) Genève: Anthropos 1977

Saint-Simon, Claude-Henri. (1817) L'industrie. En Claude-Herni Saint-Simon. Oeuvres de C.H de Saint-Simon (Tomo I-II). Genève: Anthropos, 1977.

Saint-Simon, Claude-Henri. (1819-20). L'organisateur. En Claude-Herni Saint-Simon. Oeuvres de C.H Saint-Simon (Tomo II). Genève: Anthropos, 1977.

Saint-Simon, Claude-Henri. (1820). El sistema industrial. Madrid: Ediciones de la Revista de trabajo, 1975.

Saint-Simon, Claude-Henri. (1823-24). Catéchisme des industriels. En Claude-Herni Saint-Simon. Fuvres de C.H Saint-Simon (Tomo IV). Genève: Anthropos, 1977.

Saint-Simon, Claude-Henri. (1825). Le nouveau christianisme. En Claude-Herni Saint-Simon. CEuvres de C.H de Saint-Simon (Tomo III). Genève: Anthropos, 1977.

Sérieyx, Hervé. (1993). El Big Bang de las organizaciones. Barcelona: Ediciones B, 1994.

Sewell, William H. (1980). Trabajo y Revolución en Francia. Madrid: Taurus, 1992.

Sieyès, Emmanuel. (1789). ¿Qué es el Tercer Estado?. Madrid: Alianza Editorial, 1989.

Smelser, Neil J. (1993). Le lien problématique entre différentiation et intégration. En Philippe H. Besnard, Michel Borlandi y Pierre Vogt. (Eds.). División du travail et lien social. Durkheim un siècle après (pp 259-278) París: PUF.

Soboul, Albert. (1966). Revolución Francesa. Madrid: Tecnos, 1972.

\section{Historia editorial}

Recibido: 05/11/2005

Primera revisión: 28/02/2006

Aceptado: 06/03/2006

\section{Formato de citación}

Durán, José Francisco. (2006). Durkheim y Saint-Simon: La construcción del ideario de la sociedad del trabajo y las nuevas paradojas de las sociedades tardo-modernas. Athenea Digital, 9, 152-167. Disponible en http://antalya.uab.es/athenea/num9/duran.pdf

José Francisco Durán Vázquez. Licenciado en Historia por la Universidad de Santiago. Licenciado en CC. Políticas por la Universidad de Santiago. Licenciado en Sociología por la UNED. Doctor en Sociología por la UNED. Profesor de Francés y CC. Sociales en educación secundaria. 
Durkheim y Saint-Simon: La construcción del ideario de la sociedad del trabajo y las nuevas paradojas de las sociedades tardomodernas

\section{SOMTERIGHISRESERVED}

Este texto está protegido por una licencia $\underline{\text { Creative Commons. }}$

Usted es libre de copiar, distribuir y comunicar públicamente la obra bajo las siguientes condiciones:

Reconocimiento: Debe reconocer y citar al autor original.

No comercial. No puede utilizar esta obra para fines comerciales.

Sin obras derivadas. No se puede alterar, transformar, o generar una obra derivada a partir de esta obra.

$\underline{\text { Resumen de licencia }}$

$\underline{\text { Texto completo de la licencia }}$ 